\title{
WestVirginiaUniversity
}

THE RESEARCH REPOSITORY @ WVU

Graduate Theses, Dissertations, and Problem Reports

2015

\section{Support Clean Energy: A Test of the EPPM and Psychological Reactance Theory}

Lindsey Beall

Follow this and additional works at: https://researchrepository.wvu.edu/etd

\section{Recommended Citation}

Beall, Lindsey, "I Support Clean Energy: A Test of the EPPM and Psychological Reactance Theory" (2015). Graduate Theses, Dissertations, and Problem Reports. 5169.

https://researchrepository.wvu.edu/etd/5169

This Thesis is protected by copyright and/or related rights. It has been brought to you by the The Research Repository @ WVU with permission from the rights-holder(s). You are free to use this Thesis in any way that is permitted by the copyright and related rights legislation that applies to your use. For other uses you must obtain permission from the rights-holder(s) directly, unless additional rights are indicated by a Creative Commons license in the record and/ or on the work itself. This Thesis has been accepted for inclusion in WVU Graduate Theses, Dissertations, and Problem Reports collection by an authorized administrator of The Research Repository @ WVU. For more information, please contact researchrepository@mail.wvu.edu. 
I Support Clean Energy: A Test of the EPPM and Psychological Reactance Theory

\author{
Lindsey Beall
}

\author{
Thesis submitted \\ to the Eberly College of Arts and Sciences \\ at West Virginia University \\ in partial fulfillment of the requirements for the degree of \\ Master of Arts in \\ Communication Studies
}

\author{
Matthew M. Martin, Ph.D., Chair \\ Keith D. Weber, Ed.D. \\ Elizabeth L. Cohen, Ph.D. \\ Department of Communication Studies
}

Morgantown, West Virginia

2015

Keywords: Clean Energy, Environmental Communication, EPPM, Psychological Reactance

Copyright 2015 Lindsey Beall 


\begin{abstract}
I Support Clean Energy: A Test of the EPPM and Psychological Reactance Theory

Lindsey Beall
\end{abstract}

The purpose of this study was to test components of the extended parallel process model (Witte, 1992) and psychological reactance theory (Brehm, 1966) using environmental hazards as a primary threat, rather than a personal health threat. In addition, this study examined the effect that response costs, ego involvement, and personal connection had on individuals' self-efficacy to perform a behavior. Participants $(N=157)$ watched a short video that emphasized the environmental and health risks of coal as well as the benefits of using clean energy sources. One group of participants saw a recommended response encouraging them to contact a state representative in support of clean energy initiatives. The second group did not see a recommended response. All participants answered an online survey that assessed their ego involvement involving coal, personal connection to the coal industry, efficacy regarding the recommended response, reactance regarding the video and the recommended response, intention to contact a state representative, response costs associated with contacting a state representative, and actual performed behavior where they clicked a link to receive contact information for state representatives.

Results indicated that participants who saw the video with the recommended response reported more reactance than participants who did not see the recommended response. In addition, participants who felt the video was trying to restrict their autonomy reported more reactance than participants who did not feel as if the video was trying to restrict their autonomy. Other results indicated that ego involvement involving coal had a significant, negative relationship with reported behavioral intention of contacting a state representative in support of clean energy, however, there was no relationship between ego involvement and actual performed behavior. 


\section{ACKNOWLEDGEMENTS}

The completion of this thesis would not have been possible without the guidance and dedication of my committee. First, I want to thank Dr. Matt Martin, my advisor, for believing in my research idea from the beginning. When I handed in that paper, I had no idea that it would turn into what it is today. I want to thank you for being my advisor and offering me this opportunity. Thank you for providing me with the guidance and structure to complete my thesis in a timely manner, as well as encouraging me along the way. I could not have done this without you.

Second, I want to thank Dr. Keith Weber, who is the M.A. Coordinator at West Virginia University, as well as my committee member. Dr. Weber, you not only helped shape my thesis into a final product, but you have influenced and inspired me throughout my entire master's program. Without your influence, I probably would not be going on to get a Ph.D. It was a pleasure having you as an instructor and a committee member.

Third, I want to thank Dr. Elizabeth Cohen. Your feedback has been invaluable throughout my writing process. You helped me with so many aspects of my project and I cannot express how grateful I am to you. Thank you for always believing in me in the classroom and outside of the classroom as well.

Although this instructor was not on my thesis committee, I had the wonderful opportunity to have her in class twice this past year. Dr. Christy Rittenour, you are truly a one-of-a-kind woman. You are such a happy person and can make anyone feel like they are talented and smart. Thank you for two awesome classes that I will never forget. I have learned so much from you throughout this year and I hope that you continue to inspire students professionally and personally. 
Next, I want to thank my support system and the two people who gave me life. To Mom and Dad, thank you for being the best parents anyone could have. You are the most supportive, encouraging people in the world and I know I would not be here without you. I know that any time I needed you, you would be there for me. I want to thank you both for the countless hours on the phone and in person that you spent talking with me about my research ideas. You have always supported me and my dreams. For that, I can never repay you. To Mandy, thank you for always bringing me laughter. You are such a gift to me and I know I can always talk to you when I need cheering up. I love you all so much.

I have had a wonderful experience at West Virginia University. I have met amazing people who I hope will be my lifelong friends. I am happy to call this place a home away from home. Although I will not live here forever, I will always consider myself a Mountaineer. Thank you, WVU, for being my Almost Heaven. 


\section{TABLE OF CONTENTS}

Page

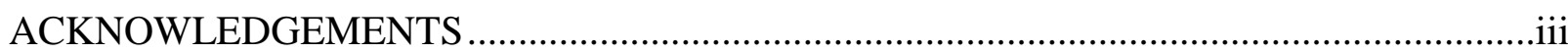

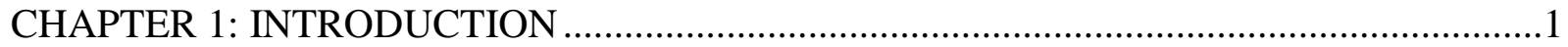

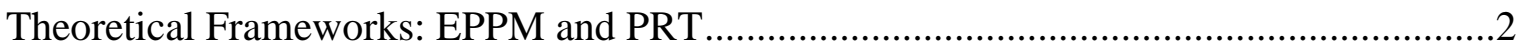

Review of the EPPM and PRT Applied to Persuasion .....................................................

Response Costs and Decision-Making................................................................................10

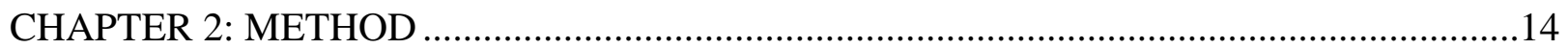

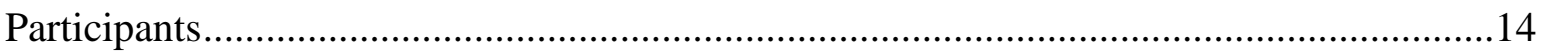

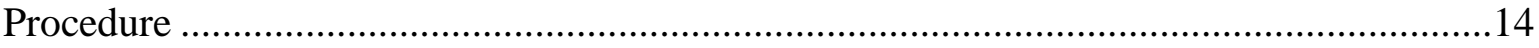

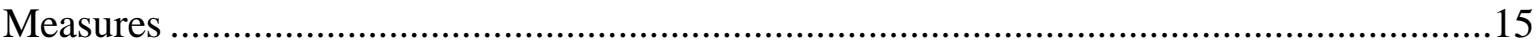

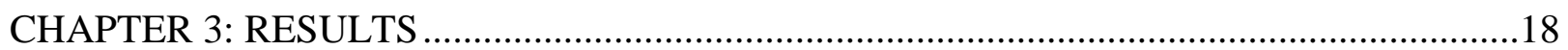

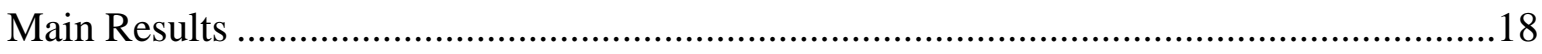

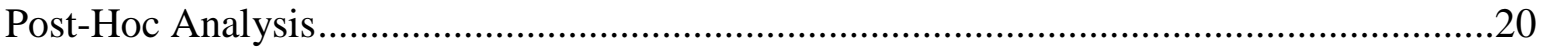

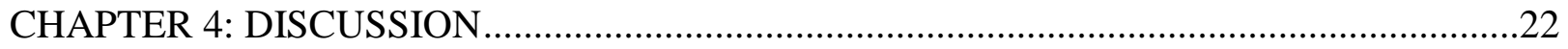

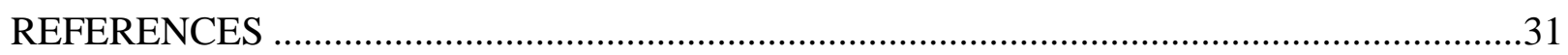

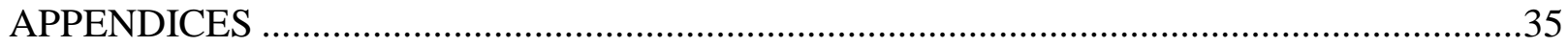

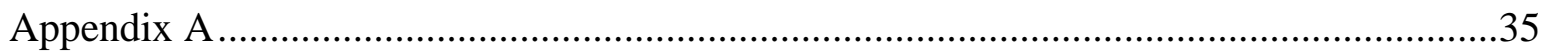

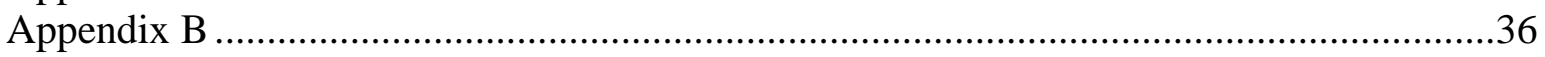

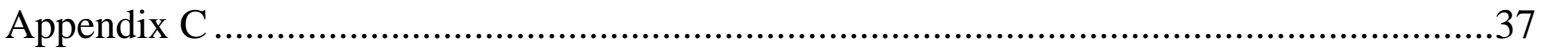

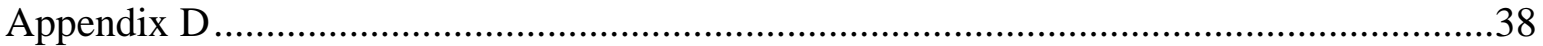

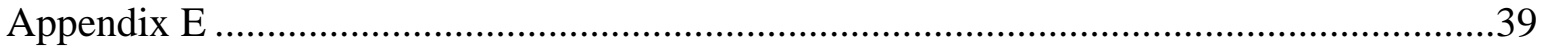

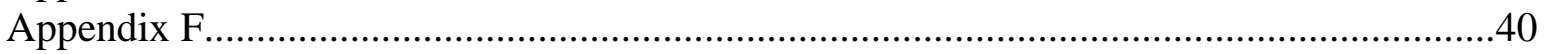

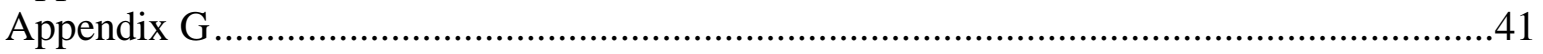

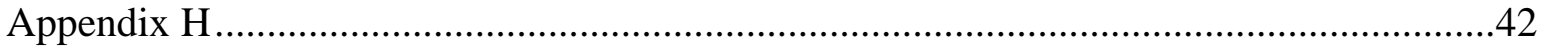

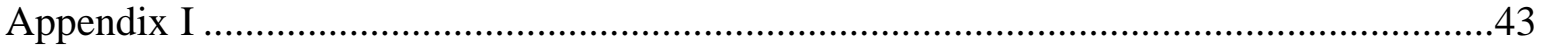

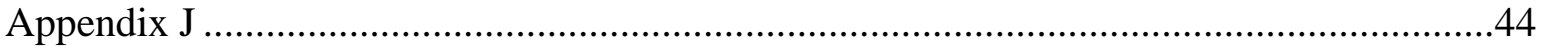

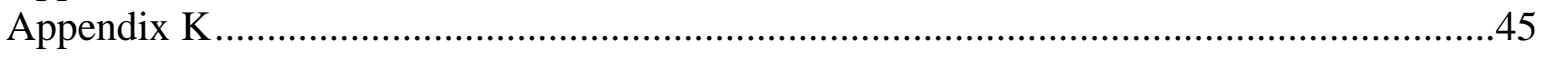




\section{CHAPTER 1: INTRODUCTION}

Fear appeals are persuasive messages that frighten people into doing what the message recommends (Witte, 1992). The typical outcome of effective fear appeals is message acceptance, defined by Witte as "attitude, intention, or behavior change." Witte proposed the extended parallel process model (EPPM), which developed the potential processes that people go through when they experience a fear appeal. The EPPM posits that when people perceive a high threat and have high self-efficacy and response efficacy, they will engage in attitude change and adaptive behaviors (Witte, 1992). Although this model is widely tested, there are some components of the decision-making process, such as response costs, that are neglected (Rintamaki \& Yang, 2014). Although Witte (1992) used components of protection motivation theory (PMT) to create the model of the EPPM, response cost was left out as an explicit variable. According to Rintamaki and Yang (2014), some people may be efficacious about a response and they may believe the response will help avoid the threat, but they may be less inclined to act because of outside factors, such as money or social influence.

Witte described message acceptance as a typical outcome of fear appeals, but individuals could completely reject the message as well. Psychological reactance theory (PRT) posits that people like their ability to behave freely and when they perceive that those behaviors are restricted, they will experience reactance and reject the message (Brehm, 1966). The purpose of this study is to test the widely-used EPPM model as well as the PRT to see if recommended responses increase individual self-efficacy and response efficacy, or if those recommended responses induce individual reactance and message rejection. In addition to testing these two theories, another purpose of this study is to include Rintamaki and Yang's adaption to EPPM by testing to see if there is a relationship between perceived responses costs and people's intentions to alter their behavior and change their attitude. 


\section{Theoretical Frameworks: EPPM and PRT}

The ultimate goal of a fear appeal is to induce an attitude, intention, or behavior change in an individual. The three main constructs of fear appeals are fear, threat, and efficacy. Fear refers to a negative emotion that is elicited by a personally significant threat (Easterling \& Levanthal, 1989). A personally relevant threat includes the ideas of perceived susceptibility, which refers to how much a message recipient feels that one is susceptible to the threat and perceived severity, which refers to the significance of the threat (Witte, 1992). In order for a fear appeal to be effective, an individual must believe that the threat is severe and that one is susceptible to that threat. The efficacy component of fear appeals includes self-efficacy, which is the strength of one's belief that one can complete a task and response efficacy, which is whether or not the recommended action will actually avert the threat (Witte, 1992).

The original parallel process model (Levanthal, 1970) offered a distinction between fear control and danger control processes. Levanthal (1970) argued that when people think about coping with their fear, rather than developing strategies to avert the impending threat, they are engaging fear control processes rather than experiencing danger control processes. Fear control processes occur when individuals attempt to stop the fear rather than the danger. They can do this by looking away from the campaign or deciding not to think about the information any further. Danger control processes occur when individuals attempt to stop the danger. They can do this by adapting their behavior, which is the goal of a fear appeal. Rogers (1975) expanded upon the danger control processes established in the parallel process model to develop the protection motivation theory. Rogers (1975) posited that three factors of fear appeals can initiate cognitive appraisals of the threat, which can lead attitude change. These factors are perceived noxiousness of the threat, the probability of the threat's occurrence, and the effectiveness of a response to avert the noxious threat (Rogers, 1975). Rogers revised the model in 1983 to not only include 
threat appraisal (i.e. severity and one's susceptibility to the threat), but also coping appraisal, which encompasses self-efficacy, response efficacy, and any costs associated with the adaptive behavior. Witte developed the EPPM by utilizing PMT's original explanation of danger control processes that lead to message acceptance and expanding upon fear control processes that lead to message rejection. Along with the original PMT, Witte used Levanthal's (1970) parallel process model as a theoretical framework for the EPPM.

According to the EPPM, individuals will go through two appraisal processes to assess the threat and efficacy components of a fear appeal (Witte, 1992). First, individuals will appraise the threat to see if it is severe and if they are susceptible to it. If the appraisal results in a high perceived threat, then fear is elicited (Easterling \& Levanthal, 1989; Witte, 1992). Once fear is elicited, individuals will move on to appraise their efficacy. If the threat appraisal results in a low threat, fear will not be elicited and the individuals will not appraise the response efficacy or their self-efficacy. When both perceived threat and perceived efficacy are high, one will be motivated to control the danger by thinking of adaptive strategies that may prevent the perceived threat from occurring, thus danger control processes will occur (Witte, 1992). When perceived threat is high, but perceived efficacy is low, fear control processes will occur. Individuals in this situation may not believe that they are able to prevent the threat or that the recommended response would not successfully abate that threat, therefore, those individuals look to handle their fear however possible, such as denying there is a problem (Witte, 1992). In order for fear appeals to be effective, danger processes must occur. If they do not, individuals will respond to the fear, not the danger, thus rejecting the message and engaging in maladaptive behaviors.

The EPPM attempts to explain how effective messages induce an attitude or behavior change using a relevant threat. The PRT, on the other hand, attempts to explain how individuals react when they perceive their freedom to be restricted by a relevant threat. According to this 
theory, people like their ability to behave freely and when they perceive that those behaviors are restricted, they will experience reactance. The magnitude of reactance can determine the action that the individuals take. The magnitude of reactance is dependent on 1) the importance of the free behavior being threatened, 2) the proportion of the behaviors being threatened, and 3) the magnitude of the threat (Brehm, 1966).

In regards to persuasive messages, individuals can perceive that communicators and messages are attempting to influence their opinions, which can be perceived as a threat to their freedom (Brehm, 1966). If individuals experience reactance from having their freedom threatened, they will attempt to re-establish that freedom by not taking the advocated position (Brehm, 1966). Although it is difficult to develop a causal relationship between experienced reactance and behavioral intent, research has addressed that perceived intent to influence opinion or action can lead to reduced behavioral intent (Dillard \& Shen, 2005).

\section{Review of the EPPM and PRT Applied to Persuasion}

When people write messages that seek a behavior change from an individual, they must make sure that the efficacy component outweighs the threat component in order to achieve the intended results (Witte, 1992). In a health context, messages that make a health issue seem more serious and likely to happen will be the most motivating, but in order for messages to induce behavior change, they must also make people believe they can accomplish the desired response and that their response will avert the threat (Witte \& Allen, 2000). Botta et al. (2011) found that when college students viewed messages that emphasized the threat of germs and the recommended response of washing hands, they felt the response was efficacious and had an influence on their behavior change. The students believed that washing hands was an effective way to reduce the threat of germs and they also felt as if they were able to wash their hands easily. After the campaign, male students washed their hands $8 \%$ more than they did before the 
campaign and women washed their hands $26 \%$ more than they did before the campaign. Similar to Botta et al.'s (2011) findings, McKay, Berkowitz, Blumberg, and Goldberg (2004) also found that groups who viewed efficacious messages, which were pamphlets that shared information about how vitamins are easy to consume and lower risk for heart disease, had significantly higher response efficacy and self-efficacy when it came to eating better and taking more vitamins.

Studies involving environmental campaigns also follow the threat and efficacy appraisal processes outlined by the EPPM. Li (2014) found that in a college setting, students who perceived a high threat in a message and reported high self-efficacy and high response efficacy were more likely to engage in danger control processes and have more positive attitudes about global warming initiatives. These students would also be more likely to engage in adaptive behaviors regarding global warming, such as purchasing recyclable products or participating in activities that pressure governments to develop solutions for the issue. Conversely, students who perceived a low threat in a message and had low self-efficacy and response efficacy were more likely to engage in fear control processes and have more negative attitudes about global warming initiatives ( $\mathrm{Li}, 2014)$. Similarly, these students were also less willing to engage in adaptive behaviors.

Although response efficacy and self-efficacy is a key to behavior adjustment, it is important to emphasize that the perceived threat is relevant to the target audience. If message recipients do not believe a perceived threat is relevant to their lives, they will not believe the threat is severe and they will not believe that they are susceptible to that threat and will not advance to appraise their efficacy (Botta et al., 2011). In regards to anti-drinking and driving on college campuses, there are certain elements that public service announcements can exhibit that will emphasize the personal relevance of drinking and driving and have a greater effect on college students (Weber, Dillow, \& Rocca, 2011). Those elements are "fear of lethal outcomes," 
"fear for others," "guilt," and "fear of non-lethal outcomes," such as parents finding out about a DUI. These elements would encourage the student to think about refraining from driving under the influence of alcohol.

Themes from this study also presented two ineffective elements, which are titled "unrealistic outcomes" and "unrealistic actions." These two ineffective elements presented no perceived threat to this target audience. In regards to unrealistic outcomes, a student referred to the common theme of hurting a child while driving drunk. This theme is often used to deter people from driving drunk because there is a possibility of hitting a child and killing them. This participant stated that "it's a little hard to relate to killing a little kid." Students in this study did not believe that they were going to hit and kill a child, so the threat of driving under the influence of alcohol was irrelevant to them, therefore, they did not change their attitude about drunk driving or intend to change their behavior. For unrealistic actions, students said that once they were out with their cars, they were not going to get a cab back to their apartment (Weber, Dillow, \& Rocca, 2011). Anti-drinking and driving public service announcements that suggest to students to call a cab are not going to elicit the desired response. Students who have their cars downtown are unlikely to leave their cars overnight and take a cab home, and then come back downtown the next day to get their car. Those elements are irrelevant and unrealistic to college students, which can explain their ineffectiveness. Similarly, Falk and Montgomery (2007) found that a major similarity of drivers between the ages of 19-23 was that they had a high awareness of the risks of risky behavior (i.e. speeding), but the concept of a serious outcome was not salient. Even though they knew that speeding was a risk that could result in serious outcomes, those outcomes were not salient, so they did not think about them while speeding.

The aforementioned research demonstrates how messages with relevant threats that lead to perceived threat severity and doable recommended responses can have a positive impact on 
behavioral change. However, the threat severity and recommended response could also induce psychological reactance, which could cause an individual to do the complete opposite (Brehm, 1966). Individuals engage in maladaptive behaviors when their freedom is threatened and they are attempting to restore that freedom. This can occur in numerous contexts, but specifically in instances of persuasion. For example, research has found that individuals who view graphic antismoking messages may be more inclined to engage in maladaptive behaviors (i.e., continuing to smoke) and understate the health behaviors associated with smoking (i.e., smoking is not that bad for my health) (Harris, Mayle, Mabbott, \& Napper, 2007).

As stated above, the findings about how message relevance relates to adaptive behaviors present mixed results regarding threat appraisal. From the EPPM perspective, topic relevance is an important component of the fear appeal. If individuals do not perceive a topic to be relevant, they will not feel that the threat is severe and they will not feel susceptible to the threat, which could affect the processes that occur. On the other hand, from a PRT standpoint, if individuals perceive a topic to be too relevant, they may feel more threatened by the message and recommended response, which could lead to maladaptive behaviors (Block \& Williams, 2002).

In addition to topic relevance, it is apparent that the effectiveness of fear appeals can depend on the message recipient's prior experience with the threat in general (Tanner, Hunt, \& Epright, 1991). In a study conducted about condom use and AIDS prevention, Tanner et al. (1991) found that previous sexual experience was a significant predictor of maladaptive behaviors. Individuals who did not use a condom beforehand were less likely to use a condom at all. Similarly, De Pelsmacker and Janssens (2007) found that habit formation directly affects one's behavioral intentions in regards to speeding. If one is used to speeding frequently, one may be more inclined to continue speeding because it is a habit.

Ego involvement has a similar effect on attitude change. Johnson and Scileppi (1969) 
found that in general, there is less attitude change when there is high ego involvement. In other words, when people receive information about a specific topic that is relevant to their personal values, they are less likely to exhibit an attitude change, regardless of the strength of the persuasive argument (Johnson \& Eagly, 1989). Conversely, Sherman, Nelson, and Steele (2000) found that when measures affirm a central value of a participant along with self-image, he or she will become less defensive and be more inclined to accept a message. In Sherman, Nelson, and Steele's study, they found that women who received messages relating caffeine consumption to breast cancer, were more likely to accept the message and adapt their behavior if they were selfaffirmed. If the message is self-image threatening, they will be less inclined to accept the message and change behavior.

This current study attempts to look at how individuals who have a central value respond to information that is threatening to that value. In this case, this study is looking at how residents of Appalachia respond to information explaining the benefits of clean energy initiatives, while explaining the effects of coal on residents' health, the economy, and the environment. The issue of coal reliance and clean energy initiatives is salient to this region. The majority of this population has a strong ego involvement regarding the coal industry. Since habit and experience is such a prominent factor in the prediction of maladaptive behavior in the studies discussed above, this study looks to test this finding and see how the habits and experiences of people who live in Appalachia affects behavioral intentions and actual performed behavior. In this case, the performed behavior will be clicking a link for state representative contact information. Although previous research has supported the finding that ego involvement and self-image regarding a certain value will impact an individual's behavioral intention, this study differentiates between personal connection, which is employment in the coal industry, and ego involvement, which measures the importance of coal to the participant. 
RQ1a: Will people who have a personal connection to the coal industry differ in behavioral intentions than people who do not have a personal connection to coal?

RQ1b: Will people who have a personal connection to the coal industry differ in whether they perform a behavior (clicking a link to receive contact information of state representative) than people who do not have a personal connection to coal?

RQ2a: How is participants' reported coal importance related to the likelihood that they will report the intention to support clean energy initiatives in Appalachia by performing behavior?

RQ2b: How is participants' reported coal importance related to the likelihood that they will support clean energy initiatives in Appalachia by performing behavior (clicking a link to receive state representative contact information)?

In order for the threat to induce the desired response of message acceptance and behavior change, the message recipient must believe that using coal as the predominant source of energy can have negative effects on health, the economy, and the environment in order to accept the message. Further, message recipients would have to believe that they are capable of supporting clean energy initiatives and that their support could make a difference in order for the message to induce an attitude change or an adjustment in behavior. In order to apply the EPPM to more environmental contexts with a broad threat of ecological consequences, rather than solely a personal threat, the following hypotheses are proposed.

H1a: Participants who view the video that emphasizes a threat and a recommended response will report a larger amount of self-efficacy than students who view the video that emphasizes a threat without the recommended response.

H1b: Participants who view the video that emphasizes a threat and a recommended response will report a larger amount of response efficacy than students who view the video that 
emphasizes a threat without the recommended response.

The ideal outcome of a fear appeal is message acceptance and behavior change. As stated above, threat severity and threat susceptibility coupled with self-efficacy and response efficacy will induce a behavior change. However, this appraisal process is not guaranteed. The aforementioned PRT literature has exemplified how some messages that provide solutions can restrict individuals' freedom of choice. When those messages display a personal threat that is perceived to be attacking an important behavior, individuals may feel as if those messages are threatening their freedom. In order to restore that freedom, individuals could decide to do the opposite of what is recommended (Brehm, 1966). Based upon the main premise of PRT, the following hypothesis are proposed.

$\mathrm{H} 2$ : Participants who view the video with emphasizes a threat and a recommended response will experience more state reactance than participants who view the video that emphasizes the threat without the recommended response.

H3: Participants' beliefs that the video threatened their autonomy will be negatively related to their behavioral intentions

\section{Response Costs and Decision-Making}

The EPPM does explain that people must have self-efficacy and response efficacy in order to accept a message, but it does not explicitly incorporate the potential costs of the recommended response that is included in an effective fear appeal (Rintamaki \& Yang, 2014). Similarly, a study involving psychological reactance regarding binge drinking acknowledges that message recipients may want to protect their health, but are aware of the social pressures of binge drinking on college campuses (Dillard \& Shen, 2005). Individuals may believe that they are unable to adjust their behavior due to those salient forces, and will perform a maladaptive behavior. 
These pressures, or response costs, are physical or psychological costs associated with engaging in a behavior. If one perceives the response cost to be too high, one may be less inclined to enact a specific behavior. In a health context, Rintamaki and Yang (2014) found that males were less likely to use condoms because of the relational cost and the sensation cost. Relational cost refers to not wanting to make his partner feel dirty because he uses a condom. Sensation cost refers to sex being as pleasurable with a condom as it is without a condom. Although these participants perceived a severe threat, had high self-efficacy about using condoms and high response efficacy, they were still reluctant to engage in adaptive behaviors. Response costs refers to individuals thinking that they can perform a behavior and that the behavior will be beneficial, however, there are outside factors that prevent them from completing this behavior.

Research on response costs as an explicit variable of the EPPM specifically is a fairly recent idea, but perceiving social costs as a barrier for behavior change has been researched previously. Tanner et al. (1991) found that social costs were not a significant predictor in condom use, but the results indicated that social costs were negatively related to adaptive behaviors, which could warrant further study.

Witte (2001) posits that response costs are a part of the self-efficacy measure in the EPPM. She argues that people who are efficacious have accounted for the response costs before deciding whether or not to enact adaptive behaviors. Rintamaki and Yang (2014) propose that response costs and perceived barriers may contribute to the self-efficacy measure, but may not be encompassed entirely by self-efficacy. The researchers slightly adapted the EPPM in order to incorporate response costs into the model as its own, explicit, variable rather than as a part of self-efficacy.

The idea of response costs is not new. Rogers (1983) incorporated response costs as an 
explicit variable in his model of protection motivation theory. Response efficacy and selfefficacy will increase the probability of danger control processes rather than fear processes. If there are less response costs, one will feel more efficacious and attempt to avert the threat rather than attempting to cope with the fear. If the response-efficacy and self-efficacy outweigh the response costs, one will be more inclined to do the adaptive behavior (Floyd, Prentic-Dunn, \& Rogers, 2000).

This proposed study includes response costs as an explicit variable because of the apparent costs of supporting clean energy initiatives, especially in Appalachia. As far back as 1983, there was a shift between the miners who made their living from coal and the environmental activists who saw the detrimental effects that strip mining had on the environment (Lewis, 1983). In today's society, the support for clean energy initiatives is steadily increasing. According to a national survey conducted by the Civil Society Institute, $80 \%$ of the 1,019 people interviewed thought that it was time to look for more ways to implement renewable energy sources (Civil Society Institute, 2012). Although people do seem to be taking initiatives to support clean energy, there are still the people who believe that supporting clean energy equates to being against coal. A purpose of this study is to see if there are perceived response costs of supporting clean energy initiatives and if that is a large reason as to why citizens of the Appalachian region are reluctant to support the clean energy movement.

As seen above, the EPPM is a widely-tested model that numerous studies have used. One goal of this study is to further the research of EPPM in an environmental context. A larger goal is to incorporate response costs as an explicit variable and what the effect that variable has on decision making in this context, if it has any effect at all.

H4: Participants who perceive no response costs in supporting clean energy by contacting a state representative would report higher self-efficacy than participants who perceive response 
costs.

RQ3a: How much of a participant's behavioral intention is predicted by their coal ego involvement, efficacy, threat attitude, response costs, or state reactance?

RQ3b: How much of a participant's performed behavior is predicted by their ego involvement, efficacy, threat attitude, response costs, or state reactance? 


\section{CHAPTER 2: METHOD}

\section{Participants}

Participants ( $n=157$; 67 males, 90 females) were recruited using snowball sampling from social media sites, such as Facebook, Twitter, and Reddit. Out of the 157 participants, 46 of them were still enrolled in college (29.3\%), followed by 25 participants with master's degrees (15.9\%), and

21 participants with bachelor's degrees (13.4\%). The average age of the participant was 35.5 years old $(S D=15.59)$ and 110 out of 157 participants lived in West Virginia $(70.1 \%)$. The study advertisement was posted on a large, mid-Atlantic university's online announcement page and sent to the faculty and staff at three universities in the mid-Atlantic region. Online participants offered a diverse sample that encompassed different age groups, geographic locations, and education levels. Participants were randomly assigned into two groups in order to limit participant bias.

\section{Procedure}

Participants in group 1 viewed a two minute video from the Sierra Club's "What's Wrong with Coal" campaign that exhibited the health and environmental risks of coal and a recommended solution that incorporated a threat and a proposed action, such as contacting a state representative. After participants viewed this clip, they completed a survey which assessed the participants' self-efficacy, response efficacy, threat attitudes about coal, state reactance, trait reactance, behavioral intentions, as well as whether the individual performed a behavior (clicked a link). Group 2 completed the same procedure, except they watched the video without the recommended response. As a manipulation check, participants were asked if they saw a recommended response encouraging them to contact a state representative at the end of the video. Results of a chi-square $(1, N=152)=76.63, p<.001$ indicated that participants recognized the manipulation. Out of 79 participants who saw the video with the recommended 
response, 68 participants indicated that they did see the recommended response encouraging them to contact a state representative in support of clean energy initiatives (86\%). Out of the 73 participants who saw the video without the recommended response, 62 indicated that they did not see the recommended response encouraging them to contact a state representative in support of clean energy initiatives $(85 \%)$.

\section{Measures}

Personal connection. Participants answered a question asking whether they or a family member was employed by the coal industry.

Ego Involvement. Participants were asked to rank the coal industry's importance to their family from 0 to 10 .

Efficacy. Participants answered questions pertaining to self-efficacy and response efficacy from an adapted Risk Diagnosis Behavior Scale (Witte, Cameron, McKeon, Berkowitz, 1996). The alpha coefficient for this self-efficacy subscale is .76 $(M=3.72, S D=1.02)$. The alpha coefficient for the response efficacy subscale is $.84(M=3.13, S D=1.15)$. The items asked questions such as, "I am able to contact my state representative to prevent encountering the environmental and health risks associated with coal that were shown in the video" or "Contacting a state representative is an effective way to help prevent future environmental and health risks associated with coal that were shown in the video." Participants answered on a 5 point Likerttype scale with 1 being strongly disagree and 5 being strongly agree.

Threat Perception. Participants answered questions pertaining to attitude about coal and clean energy from an adapted Risk Diagnosis Behavior Scale (Witte et al., 1996). The alpha coefficient for this subscale is $.84(M=4.03, S D=1.09)$. Two items regarded the severity of a threat and asked "I believe that the environmental and health risks associated with coal that were shown in the video are severe." The other items regarded the participants' perceived 
susceptibility of the threat and ask "It is possible that I will encounter the environmental and health risks associated with coal that were shown in the video." Participants answered on a 5 point Likert-type scale with 1 being strongly disagree and 5 being strongly agree.

Response Costs. Participants were prompted to answer an open ended question asking some reasons that they or a family member would be reluctant to support clean energy initiatives and why. If participants have no response, they will be prompted to write N/A in the space provided.

State Reactance. This measure included three subscales and was adapted from previous research (e.g. Dillard \& Shen, 2005; Quick, 2011) by Gardner in 2010. The first subscale was perceived threat to choice, which asked the participant whether the video hindered their ability to choose freely $(M=2.49, S D=1.22, \alpha=.89)$. The second was counter-arguing, which asked the participants to answer whether the video caused them to be skeptical of the message $(\mathrm{M}=1.68$, $S D=.65, \alpha=.88)$. The final subscale was anger, which asked participants whether the video made them feel certain negative emotions, such as irritation, anger, annoyance $(M=1.86, S D=$ $1.00, \alpha=.92)$.

Trait Reactance. Participants answered questions that assessed their reactance to compliance, such as "When something is prohibited, I usually think, 'that's exactly what I am going to do." The alpha coefficient for that subscale is $.65(M=2.16, S D=.77)$. The next subscale assessed participants' reactance toward restricted choice, such as "I become frustrated when I am unable to make free and independent decisions." The alpha coefficient for this subscale is $.81(M=3.25, S D=1.04)$. The third subscale assessed participants' reactance toward advice and recommendations, such as "Advice and recommendations usually induce me to do just the opposite." The alpha coefficient for this subscale is $.83(M=1.82, S D=.67)$. This measure was adapted from Hong and Page's (1989) trait reactance scale. 
Behavioral Intentions. Participants answered a question asking how likely they were to contact a state representative in support of clean energy initiatives. Participants answered on a 5 point Likert scale with 1 representing strongly disagree and 5 representing strongly agree.

Behavior Performance. At the end of the survey, participants were asked if they would like to receive contact information for state representatives. Participants clicked yes to be taken to the webpage link and no to exit the survey. 


\section{CHAPTER 3: RESULTS}

\section{Main Results}

Research question 1a asked whether participants who had a personal connection to the coal industry (group 1) would differ more in behavioral intentions than participants who did not have a personal connection to the coal industry (group 2). Results of an ANOVA indicated that there was no significant difference between group 1 and group $2(F(1,154)=2.06, \mathrm{p}=.15)$. Participants who had a personal connection to the coal industry $(M=3.14, S D=1.48)$ did not differ in their behavioral intentions from participants who did not have a personal connection to the coal industry $(M=2.82, S D=1.26)$.

Research question $1 \mathrm{~b}$ asked whether people who had a personal connection to the coal industry (group 1) would differ in behavior performance than people who did not have a personal connection to the coal industry (group 2 ). Results of a chi-square $(1, N=149)=1.90, p=.17$ indicated there was no significant relationship. Participants who reported a personal connection to the coal industry did not differ in behavior performance from people who did not report a connection to the coal industry.

Research question 2a asked how participants' reported ego involvement involving coal was related to their behavioral intentions of contacting a representative in support of clean energy initiatives. Results of a correlation indicated that there was a significant, negative relationship between participants' reported ego involvement involving coal and their intention to support clean energy initiatives $(r=-.38, p<.001)$.

Research question $2 \mathrm{~b}$ asked how participants' reported ego involvement involving coal was related to their behavior performance of clicking a link to receive contact information of a state representative. Results of an independent samples $t$-test showed that there was no significant difference between the participants who chose to click the link and the participants 
who chose not to click $(t(147)=1.38, p=.18)$. Participants who chose to click for contact information $(M=6.12, S D=3.22)$ did not show a significant difference in ego involvement than participants who chose not to click for contact information $(M=5.19, S D=3.22)$.

Hypothesis 1a predicted that individuals who watched the video with a recommended response would report more self-efficacy than individuals who watched the video with no recommended response. Results of an independent samples $t$-test did not support this hypothesis $(t(153)=1.18, p=.24)$. Participants who watched the video with a recommended response $(M=$ $3.81, S D=.90)$ did not differ significantly from participants who watched the video with no recommended response $(M=3.62, S D=1.11)$.

Hypothesis $1 \mathrm{~b}$ forwarded that individuals who watched the video with the recommended response would report more response efficacy than individuals who watched the video with no recommended response. Results of an independent samples t-test did not support this hypothesis $(t(152)=.37, \mathrm{p}=.36)$. Participants who watched the video with the recommended response $(M=$ $3.16, S D=1.10)$ did not differ from the participants who watched the video without the recommended response $(M=3.09, S D=1.20)$ when reporting response efficacy.

Hypothesis 2 forwarded that participants who viewed the video with a recommended response would report more state reactance than participants who viewed the video without a recommended response. Results of an ANOVA indicated that the model was significant $(F(1,150)=3.87, p=.03)$. Participants who viewed the video with a recommended response $(M$ $=2.13, S D=.88)$ reported more state reactance than participants who viewed the video without a recommended response $(M=1.87, S D=.73)$.

Hypothesis 3 predicted that participants' beliefs that the video threatened their autonomy would be negatively related to their behavioral intention of contacting a state representative. This was measured by a subscale in the state reactance measure. Results of a correlation supported 
this hypothesis $(r=-.45, p<.001)$. There is a significant, negative relationship between a participants' belief that the video threatened their autonomy and their behavioral intentions.

Hypothesis 4 predicted that participants who perceived no response costs in supporting clean energy by contacting a state representative would report higher self-efficacy than participants who perceived response costs. Results of an independent samples $t$-test did not support this hypothesis $(t(153)=.229, p=.82)$. Participants who perceived no response costs $(M$ $=3.73, S D=1.49)$ did not differ in their self-efficacy from participants who perceived response costs $(M=3.69, S D=.96)$.

Research question 3a asked how much of participants' behavioral intention is predicted by their ego involvement involving coal, efficacy, threat attitude, response costs, or state reactance. Results of a Regression analysis indicated the overall model fit was $R^{2}=.55$. The analysis showed that threat severity $(\beta=.36, t=4.90, p<.001)$, self-efficacy $(\beta=.20, t=3.02, p$ $=.002)$, and response efficacy $(\beta=.36, t=5.34, p<.001)$ are significant predictors of a participant's behavioral intention. Results indicated that ego involvement involving coal $(\beta=$ $.00, \mathrm{t}=.01, p=.99)$ and response costs $(\beta=-.06, t=-.97, p<.33)$ were not significant predictors of the model.

Research question $3 \mathrm{~b}$ asked whether a participant's performed behavior is predicted by their ego involvement involving coal, efficacy, threat attitude, response costs, or state reactance. Results of a Logistic Regression indicated that this model was not significant $X^{2}(6)=5.47, p=$ .49. These variables did not predict participants' likelihood to perform a behavior.

\section{Post-Hoc Analysis}

Two post hoc analyses were conducted. The first one involved hypothesis two which stated that participants who viewed the video with a recommended response would report more state reactance than participants who viewed the video without a recommended response. A post 
hoc ANCOVA was conducted in order to control for trait reactance $(F(2,149)=17.77, p<.001)$. Whether a participants viewed the recommended response or not had a significant effect on participants' state reactance when controlling for trait reactance $(F(1,149)=30.91, p<.001$. The variance accounted for when controlling for trait reactance was $R^{2}=.19$. The model that did not have trait reactance as a covariate was still statistically significant $(F(1,150,3.87, p=.03)$, however, the variance accounted for was $R^{2}=.03$.

As a follow up to RQ3a, partial correlations were looked at to observe unique relationships between the various variables with behavioral intention while controlling for the other variables. Three of the relationships remained significant: threat severity $(r=.38, p<$ $.001)$, self-efficacy $(r=.25, p<.05)$, and response efficacy $(r=.41, p<.001)$. The correlations that were no longer significant involved ego involvement $(r=.00, p=.99)$, state reactance $(r=-$ $.08, p=.32)$, and response costs $(r=-.08, p=.33)$. 


\section{CHAPTER 4: DISCUSSION}

This study tested two theories, the extended parallel process model (Witte, 1992) and psychological reactance theory (Brehm, 1966), as well as other variables that could possibly predict individuals' behavioral intention and performed behavior. The findings from this study showed that the recommended response shown after the video did not impact participants' selfefficacy or response efficacy. The EPPM was only partially supported in this context, but findings from the study supported central tenets of psychological reactance theory regarding one's autonomy and experienced reactance.

Participants who viewed the video with the recommended response to contact a state representative in support of clean energy initiatives did not differ significantly in their reported self-efficacy than participants who viewed the video without a recommended response. Similarly, participants who viewed the video with the recommended response did not differ significantly in their reported response efficacy from participants who viewed the video without a recommended response. The results also indicated that there was not a significant difference between participants who viewed the recommended response and the participants who did not in terms of threat severity. Both groups reported the threat to be severe, however, the groups did not differ in their efficacy regardless of which message they saw. Witte (1992) posited that individuals who perceive a threat to be severe, but are given a recommended response to help avert that threat will feel greater self-efficacy and response efficacy than individuals who perceive a threat is high, but are given no recommended response. These results did not support the efficacy component of the EPPM.

Possibly the recommended response was not strong enough to make a significant difference in addition to the video. In other words, the video itself may have been strong enough on its own that the treatment of the recommended response did not have a significant effect on 
reported self-efficacy or reported response efficacy. The video presented a one-sided argument that explained why coal was bad and why clean energy was good. Since the threat was portrayed in such a severe manner, the recommended response was unable to impact participants' selfefficacy and response efficacy. The participants who viewed the video with the recommended response may have thought that contacting a state representative in support of clean energy initiatives was not strong enough to avert the threat portrayed in the video.

As a part of the adapted EPPM that Rintamaki and Yang (2014) proposed, one of the hypotheses tested whether perceived response costs would affect perceived self-efficacy. The hypothesis predicted that individuals who perceived zero response costs, or social barriers, to supporting clean energy initiatives (i.e., coal culture, jobs, economy, etc.) would report more self-efficacy than individuals who did perceive response costs. Rintamaki and Yang (2014) stated response costs could potentially affect an individual's ability to accept a message or make a behavior change. In the current study, the idea of response costs as an explicit variable of the EPPM is not supported. The response costs were coded as reasons why individuals would not contact a state representative in support of clean energy. Based upon these results, response costs did not have a significant relationship with individuals' perceived self-efficacy in regards to contacting a state representative. This could be due to the magnitude of the response costs. Although individuals perceive social barriers to supporting clean energy, the response costs may not be salient enough to impact perceived self-efficacy.

The results of this study present mixed findings in regards to the EPPM. As seen above, the aforementioned findings have not supported the central tenets of the EPPM. There was no significant difference between individuals who saw the recommended response from individuals who did not see the recommended response in terms of threat severity. This means that even though both groups perceived the threat to be equally severe, the recommended response did not 
impact participants' self-efficacy or response efficacy. These results do not support previous findings that show that a recommended response will have a positive relationship with efficacy (Botta, et al., 2011). Although some of these results tend to reject the EPPM's central tenets in this context, it appears that other results provide some support for the EPPM. When predicting individuals' intent to contact a state representative to support clean energy initiatives, threat severity, self-efficacy, and response efficacy were the only significant predictors of behavioral intention. Similarly, when controlling for all of the other variables in this model, threat severity, self-efficacy, and response efficacy were the only three variables that remained significant. These findings support the EPPM's central tenets that threat severity, self-efficacy, and response efficacy will have an effect on individuals' behavior intention.

Overall, the findings supported psychological reactance theory more than they supported the EPPM. The PRT posits that individuals who feel that their freedom is being restricted will experience reactance and attempt to restore that freedom by rejecting the recommended behavior and engaging in the opposite behavior (Brehm, 1966). In this study, individuals who watched the video with the recommended response reported more state reactance than the individuals who watched the video without the recommended response. Both groups viewed the same video, but only one had the treatment, so this finding exhibits that the individuals who viewed the recommended response felt that it was restricting their freedom to choose by encouraging them to contact a state representative in support of clean energy initiatives. The treatment's effect when tested in PRT is different than when it was tested in the EPPM. The recommended response in PRT invoked more reactance than the video alone. The recommended response in the EPPM, however, did not invoke greater self-efficacy or response efficacy than the video alone. The findings support the component of PRT which states that individuals who believe their freedom has been restricted will be less inclined to do the recommended behavior. 
Hypothesis 3 predicted that participants' beliefs about the video restricting their autonomy would be negatively related to their behavioral intention. The results indicated that when participants believe that the video and treatment threatened their ability to choose what to do, they felt less inclined to do the recommended behavior of contacting a state representative in support of clean energy initiatives. This finding aligns with PRT in that when people believe that their autonomy is threatened, they will experience reactance. When individuals experience reactance, they will attempt to restore that freedom by engaging in maladaptive behaviors (Brehm, 1996).

Besides testing the two theories, several research questions asked whether a personal connection or ego involvement involving coal would influence behavioral intention and behavior performance. Participants who had a personal connection to coal by having a family member employed by the coal industry did not express a desire to contact a state representative any more than participants who did not have a personal connection. Similarly, participants without a personal connection did not perform the behavior more than participants with a personal connection.

In terms of ego involvement, as individuals' ego involvement involving coal increased, their intentions of contacting a state representative in support of clean energy decreased. This finding affirms previous research that when people place personal importance on a certain value, they will link a message topic to that value and reject the behavior change (Johnson \& Eagly, 1989). The respondents who had higher ego involvement involving coal were less likely to contact a state representative.

Individual's connection to the coal industry did not have a significant relationship with one's behavioral intention or performed behavior, however, ego involvement involving coal did have a significant relationship with one's behavior intention. This finding implies that the importance of coal industry to the participants, is more meaningful to the participant than being 
employed by the coal industry.

This study has five limitations that should be discussed. The first limitation of this study involves the generalizability of the study. The methods of this study could have hindered the generalizability to the results. The survey was distributed entirely online, which could have affected the participants who responded. In order to complete the survey, participants had to have seen the link online through social media platforms or email and completed it on a computer. Residents of rural Appalachia may not have the technological resources to complete the survey, therefore the results may have been biased for those participants who have the resources to watch the video and complete the survey.

This could be addressed by providing paper versions of the questionnaire and offering to play the video at a central location, which may have computers. This solution would require funding and time, but it could probably reach more of the target population than just an online questionnaire found on social media or through email lists.

A second limitation of this study involves the strength of the manipulation. Although participants did notice the manipulation, there was no difference between the group who viewed the video without the recommended response and the group who viewed the video with the recommended response. This affirms the idea that the manipulation was not powerful enough to influence participants' self-efficacy or response efficacy regarding contacting a state representative or maybe, participants did not view the consequences associated with coal reliance as a severe threat. The strength of the manipulation could be increased by providing individuals with options of responses that they felt could actually avert the threat, such as giving a monetary donation to a clean energy company.

A third limitation of the study is the video's one-sided message. The video presented reasons why relying on coal is dangerous and why supporting clean energy initiatives is 
beneficial. The video was developed by the Sierra Club as part of the "What's Wrong with Coal" campaign. The biased information presented could have contributed to the reactance experienced by the participant, rather than just the manipulation itself.

The fourth limitation of this study is how the response cost variable was operationalized. The survey asked participants to give reasons why they would be reluctant to contact a state representative in support of clean energy initiatives. Many of the responses given had to do with efficacy rather than response costs. Participants said they would not contact a state representative in support of clean energy initiatives because they did not think that contacting a state representative would be effective. This is response efficacy, not a response cost. The response costs should have been directly related to contacting a state representative and why participants would be hesitant to perform that behavior.

Another limitation of this study is the adaptation of the Risk Behavior Diagnosis scale (Witte et al., 1996). This scale has been used predominantly in health contexts. For the purposes of this study, it was adapted to include environmental threats, as well as health threats. The items were adapted to ask the participants whether they perceived the environmental and health risks in the video to be severe, whether they were likely to encounter these risks, and whether the response of contacting a state representative is an effective way to avert these risks. The wording of the items can be problematic because it presents the participant with a double barreled question. They are forced to place the threats shown in the video into two categories, when they may believe that the threats fell into a completely different category than "environmental" or "health." This could have influenced the results of the efficacy and threat dimensions of this study.

Although there are limitations, this study has provided insight that can be used for further research. As stated above, the video itself was a powerful message and the manipulation had no 
significant effect on either group. A future direction of this study is to present a message that exhibits both pro-coal and pro-clean energy initiatives and allows the participant to make an assessment. This may provide the participant with more self-efficacy to complete the recommended response. Also, a two-sided message could provide the participants with factual information about coal reliance and the benefits of clean energy. This message could decrease individuals' experienced reactance because they may not feel like the video is as threatening to their freedom of choice.

Similarly, a future direction of this study could be to allow individuals the option to become a "friends of coal" supporter or to contact a state representative in support of coal. This option would test true reactance. This study was limited in that it only tested the participants' experienced reactance. Some participants reported that they thought the video restricted their autonomy and they chose not to receive contact information for state representatives. If there was an option to become a "friend of coal" or to contact a state representative in support of coal, some participants may have done that in order to restore the freedom that the video restricted.

Another future direction from this study could be to look at response costs qualitatively. For the purposes of this study, the response cost variable was used quantitatively and measured as a reason why someone would be reluctant to contact a state representative in support of clean energy initiatives. The number of response costs was coded by whether a participant listed one or more or zero, rather than the content. The frequency of response costs was predicted to have a negative relationship with self-efficacy. In other words, if participants perceived more response costs, they would report less self-efficacy than participants who perceived zero response costs. The findings presented that the number of response costs had no significant relationship with participants' self-efficacy.

To better understand the role that response costs play in influencing people's attitudes 
and behaviors, response costs could be coded by content rather than frequency. Researchers could find common themes among participants for why they would be hesitant to support clean energy initiatives. An example of a theme would be job security. Respondents listed that people may be hesitant to support clean energy initiatives because their family has been employed by the coal industry for years. It is their source of income and a part of their livelihood. Another theme could be that contacting a state representative would take too much time and effort. Some participants just did not want to contact a state representative because it took too much effort. Identifying these themes could provide researchers with social barriers that are most salient to the target population and help develop more effective messages to encourage the public to support clean energy initiatives in the Appalachian Region.

Another future direction of this study could be to see how behavioral intention differs from performed behavior in terms of ego involvement and see why that variable impacts those behavioral intention and performed behavior differently. The findings from the study present that ego involvement had a significant, negative relationship with intention to contact a state representative, however, it had no significant relationship with performed behavior. Future studies could see what barriers keep people from actually completing a behavior when they report the intention to do that behavior.

Overall, this study attempted to expand the EPPM to a context that it has not been studied previously. The EPPM could be studied more in contexts where there is a salient threat, but it is not a personal threat. In the health literature, the EPPM is used with personal threats and recommended responses (e.g. Botta et al., 2011; Weber, Dillow, \& Rocca, 2011). This study used a threat that had potential environmental impacts as well as personal impacts. The recommended response, however, was less personal and it was difficult to make the connection between contacting a state representative and averting the threat of sickness among children, 
financial troubles, and environmental issues. Future studies could continue to test the EPPM in contexts where the threat is personal, but the available recommended responses are not to see if the theory is supported.

This study tested two different theoretical frameworks and attempted to identify which one better explained behavioral intention and performed behavior. The extended parallel process model did not hold up in the primary findings, however, when controlling for all other predictive variables, threat severity, self-efficacy, and response efficacy were the only significant predictors of participants' behavioral intentions. The tenets of psychological reactance theory were mostly supported in this study. Individuals who experienced reactance were less likely to support clean energy initiatives in the Appalachia region. Participants who felt that the video was restricting their autonomy also were less likely to support clean energy initiatives. In addition to testing these theories, this research also sought to test whether ego involvement had a relationship with behavioral intention and performed behavior. This research supports the idea that individuals who had ego involvement involving coal were less likely to support clean energy initiatives. 


\section{References}

Block, L. G., \& Williams, P. (2002). Undoing the effects of seizing and freezing: Decreasing defensive processing of personally relevant messages. Journal of Applied Social Psychology, 32, 803-830. doi:10.1111/j.1559-1816.2002.tb00243.x

Botta, R. A., Dunker, K., Fenson-Hood, K., Maltarich, S., \& McDonald, L. (2008). Using a relevant threat, EPPM and interpersonal communication to change hand-washing behaviors on campus. Journal of Communication in Healthcare, 1, 373-381. doi: 10.1179/cih.2008.1.4.373

Brehm, J. W. (1966). A theory of psychological reactance. New York: Academic Press.

Brulle, R. J. (2010). From environmental campaigns to advancing the public dialog: Environmental communication for civic engagement. Environmental Communication, 4, 82-98. doi: 10.1080/17524030903522397

Cauberghe, V., De Pelsmacker, P., Janssens, W., \& Dens, N. (2009). Fear, threat and efficacy in threat appeals: Message involvement as a key mediator to message acceptance. Accident Analysis \& Prevention, 41, 276-285. doi:10.1016/j.aap.2008.11.006

Clean Society Institute. (2012, April 25). National Survey Results: Bipartisan Majority of Americans Want Clean Energy [Press release]. Retrieved from https://www.kftc.org/press/releases

De Pelsmacker, P., \& Janssens, W. (2007). The effect of norms, attitudes and habits on speeding behavior: Scale development and model building and estimation. Accident Analysis \& Prevention, 39, 6-15. doi:10.1016/j.aap.2006.05.011

Dillard, J.P., \& Shen, L. (2005). On the nature of reactance and its role in persuasive health communication. Communication Monographs, 72, 144-168.

doi:10.1080/03637750500111815 
Easterling, D. V., \& Leventhal, H. (1989). Contribution of concrete cognition to emotion: Neutral symptoms as elicitors of worry about cancer. Journal of Applied Psychology, 74, 787-796. doi:10.1037/0021-9010.74.5.787

Falk, B., \& Montgomery, H., (2007). Developing traffic safety interventions from conceptions of risks and accidents. Transportation Research Part F: Psychology and Behaviour, 10, 414-427. doi:10.1016/j.trf.2007.04.001

Floyd, D., Prentice-Dunn, S., \& Rogers, R. (2000), A meta-analysis of research on protection motivation theory. Journal of Applied Social Psychology, 30, 407-429. doi: 10.1111/j.1559-1816.2000.tb02323.

Gardner, E. (2010). Ease the resistance: The role of narrative and other-referencing in attenuation psychological reactance to persuasive diabetes messages. Unpublished doctoral dissertation, University of Missouri, Columbia, MO.

Harris, P. R., Mayle, K., Mabbott, L., \& Napper, L. (2007). Self-affirmation reduces smokers' defensiveness to graphic on-pack cigarette warning labels. Health Psychology, 26, 437446. doi:10.1037/0278-6133.26.4.437

Hong, S. M., \& Page, S. (1989). A psychological reactance scale: Development, factor structure and reliability. Psychological Reports, 64, 1323-1326.

Johnson, B. T., \& Eagly, A. H. (1989). Effects of involvement on persuasion: A meta-analysis. Psychological Bulletin, 106, 290-314. doi:10.1037/0033-2909.106.2.290

Johnson, H. H., \& Scileppi, J. A. (1969). Effects of ego-involvement conditions on attitude change to high and low credibility communicators. Journal of Personality and Social Psychology, 13, 31-36. doi:10.1037/h0027992

Leventhal, H. (1970). Findings and theory in the study of fear communications. In L. Berkowitz (Ed.). Advances in experimental social psychology (pp. 119-186). New York: 
Academic Press.

Lewis, H. (1983). Wales and Appalachia—Coal Mining, Culture, and Conflict. Appalachian Journal, 10, 350-357. Retrieved from http://www.jstor.org/stable/40932534.

Li, S. (2014). Fear Appeals and College Students' Attitudes and Behavioral Intentions toward Global Warming. The Journal of Environmental Education, 45, 243-257. doi: $10.1080 / 00958964.2014 .930399$

McKay, D., Berkowitz, J., Blumberg, J., \& Goldberg, J. (2004). Communicating cardiovascular disease risk due to elevated homocysteine levels: Using the EPPM to develop print materials. Health Education and Behavior, 31, 355-371. doi:10.1177/1090198104263353

Rintamaki, L., \& Yang, J. (2014). Advancing the extended parallel process model through the inclusion of response cost measures. Journal of Health Communication International Perspectives, 19, 759-774. doi: 10.1080/10810730.2013.864722

Rogers, R. W. (1975). A protection motivation theory of fear appeals and attitude change. Journal of Psychology, 91, 93-144. doi: 10.1080/00223980.1975.9915803

Rogers, R.W. (1983). Cognitive and physiological processes in fear appeals and attitude change: A revised theory of protection motivation. In J. Cacioppo \& R. Petty (Eds.), Social psychophysiology (pp. 153-176). New York: Guilford.

Tanner, J., Hunt, J., \& Eppright, D. (1991). The protection motivation model: A normative model of fear appeals. Journal of Marketing, 55, 36-45. doi:10.2307/1252146

U.S. Census Bureau. (2010). The Appalachian region in 2010: A census data overview. Retrieved from http://www.prb.org/pdf12/appalachia-census-chartbook-2011.pdf

Weber, K., Dillow, M. R., \& Rocca, K. A. (2011). Developing and testing the antidrinking and driving PSA. Communication Quarterly, 59, 415-427. 
Doi: 10.1080/01463373.2011.597285

Witte, K. (1992). Putting the fear back into fear appeals: The extended parallel process model. Communication Monographs, 59, 329-349. doi: 10.1080/03637759209376276

Witte, K., \& Allen, M. (2000). A meta-analysis of fear appeals: Implications for effective public health campaigns. Health Education and Behavior, 27, 591-615. doi: $10.1177 / 109019810002700506$

Witte, K., Cameron, K. A., McKeon, J. K., \& Berkowitz, J. M. (1996). Predicting risk behaviors: Development and validation of a diagnostic scale. Journal of Health Communication, 1, 317-341. doi: 10.1080/108107396127988

Witte, K., Meyer, G., \& Martell, D. (2001). Effective health risk messages: A step-by-step guide. Thousand Oaks, California: Sage Publications. 
Appendix A

Please indicate your education level?

Some high school High school diploma Some college Bachelor's degree

Some graduate courses Master's degree Doctoral degree

Still enrolled in college

What is your age?

Please indicate your sex Male Female

Please indicate the state in which you live ___ (drop down)

If you live in $\mathrm{WV}$, please indicate your permanent county __ (drop down) 


\section{Appendix B}

Personal connection

Does anyone in your family work in the coal industry? Yes No 


\section{Ego Involvement}

\section{Appendix C}

Please note your level of agreement with the following statement from 0 to 10 , with 0 representing strongly disagree and 10 representing strongly agree.

The use of coal is an important issue to my family and/or to me. 
Efficacy

\section{Appendix D}

1 is strongly disagree, 2 is somewhat disagree, 3 is neutral, 4 is somewhat agree, 5 is strongly agree.

Contacting a state representative is an effective way to help prevent future environmental and health risks associated with coal that were shown in the video:

$\begin{array}{lllll}1 & 2 & 3 & 4 & 5\end{array}$

If I contact a state representative, it would have no impact on the environmental and health risks shown in the video:

$\begin{array}{lllll}1 & 2 & 3 & 4 & 5\end{array}$

I am able to contact my state representative to prevent encountering the environmental and health risks associated with coal that were shown in the video:

$\begin{array}{lllll}1 & 2 & 3 & 4 & 5\end{array}$

Contacting a state representative to prevent the environmental and health risks associated with coal that were shown in the video is something I can easily do.

$\begin{array}{lllll}1 & 2 & 3 & 4 & 5\end{array}$




\section{Threat Attitude}

\section{Appendix E}

1 is strongly disagree, 2 is somewhat disagree, 3 is neutral, 4 is somewhat agree, 5 is strongly agree

I believe that the environmental and health risks associated with coal that were shown in the video are severe:

$\begin{array}{lllll}1 & 2 & 3 & 4 & 5\end{array}$

I believe that the environmental and health risks associated with coal that were shown in the video have serious negative consequences:

$\begin{array}{lllll}1 & 2 & 3 & 4 & 5\end{array}$

It is likely that I will encounter the environmental and health risks associated with coal that were shown in the video:

$\begin{array}{lllll}1 & 2 & 3 & 4 & 5\end{array}$




\section{Behavioral Intention}

\section{Appendix F}

1 is strongly disagree, 2 is somewhat disagree, 3 is neutral, 4 is somewhat agree, 5 is strongly agree.

I am likely to contact a state representative to express my support for clean energy initiatives in the Appalachian region.

$\begin{array}{lllll}1 & 2 & 3 & 4 & 5\end{array}$




\section{Response Costs}

\section{Appendix G}

Are there reasons why you or a family member would be hesitant to support clean energy initiatives? If so, what are they? If not, please indicate N/A. 
State Reactance

\section{Appendix $\mathrm{H}$}

1 is strongly disagree, 2 is somewhat disagree, 3 is neutral, 4 is somewhat agree, 5 is strongly agree

The video threatened my freedom to choose:

The video tried to make a decision for me:

$\begin{array}{lllll}1 & 2 & 3 & 4 & 5\end{array}$

The video tried to manipulate me:

$\begin{array}{lllll}1 & 2 & 3 & 4 & 5\end{array}$

$\begin{array}{lllll}1 & 2 & 3 & 4 & 5\end{array}$

1 is not at all, 2 is rarely, 3 is sometimes, 4 is frequently, 5 is always

Did you criticize the video you just saw while you were viewing it?

$$
\begin{array}{lllll}
1 & 2 & 3 & 4 & 5
\end{array}
$$

Did you think of points that went against what was being said while you were viewing the video?

$\begin{array}{lllll}1 & 2 & 3 & 4 & 5\end{array}$

While viewing the video, were you skeptical of what was being said?

$\begin{array}{lllll}1 & 2 & 3 & 4 & 5\end{array}$

1 is not at all, 2 is a little angry, 3 is neutral, 4 is somewhat angry, 5 is very angry

To what extent did this message make you feel...

Irritated

Angry

Annoyed

$\begin{array}{lllll}1 & 2 & 3 & 4 & 5\end{array}$

$\begin{array}{lllll}1 & 2 & 3 & 4 & 5\end{array}$

$\begin{array}{lllll}1 & 2 & 3 & 4 & 5\end{array}$




\section{Appendix I}

\section{Trait Reactance}

1 is strongly disagree, 2 is somewhat disagree, 3 is neutral, 4 is somewhat agree, 5 is strongly agree

\section{Factor: Reactance to Compliance}

Regulations trigger a sense of resistance in me.

$\begin{array}{lllll}1 & 2 & 3 & 4 & 5\end{array}$

I find contradicting others stimulating.

$\begin{array}{lllll}1 & 2 & 3 & 4 & 5\end{array}$

When something is prohibited, I usually think, "That's exactly what I am going to do."

$$
\begin{array}{lllll}
1 & 2 & 3 & 4 & 5
\end{array}
$$

\section{Factor: Emotional Response toward Restricted Choice}

I become frustrated when I am unable to make free and independent decisions.

$$
\begin{array}{lllll}
1 & 2 & 3 & 4 & 5
\end{array}
$$

It irritates me when someone points out things which are obvious to me.

$$
\begin{array}{lllll}
1 & 2 & 3 & 4 & 5
\end{array}
$$

I become angry when my freedom of choice is restricted.

$\begin{array}{lllll}1 & 2 & 3 & 4 & 5\end{array}$

\section{Factor: Reactance toward Advice and Recommendations}

I consider advice from others to be an intrusion.

$\begin{array}{lllll}1 & 2 & 3 & 4 & 5\end{array}$

Advice and recommendations usually induce me to do just the opposite.

$\begin{array}{lllll}1 & 2 & 3 & 4 & 5\end{array}$




\section{Performed Behavior}

\section{Appendix $\mathbf{J}$}

If you would like to be taken to a web page that provides the contact information of state representatives, please choose yes. $\mathrm{Y} \quad \mathrm{N}$ 
Appendix K

Manipulation Check

At the end of the video, I saw a message suggesting that I contact a state representative in support of clean energy initiatives. T F 